\title{
Clinical hypoxic-ischemic encephalopathy score of the Iberoamerican Society of Neonatology (Siben): A new proposal for diagnosis and management
}

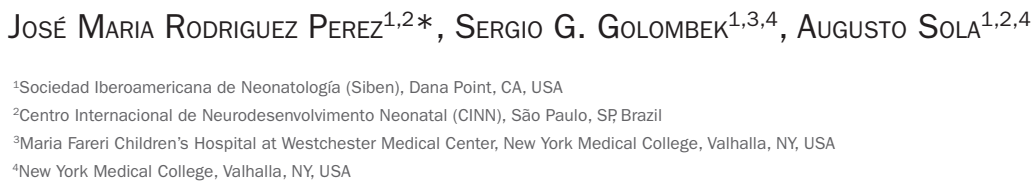

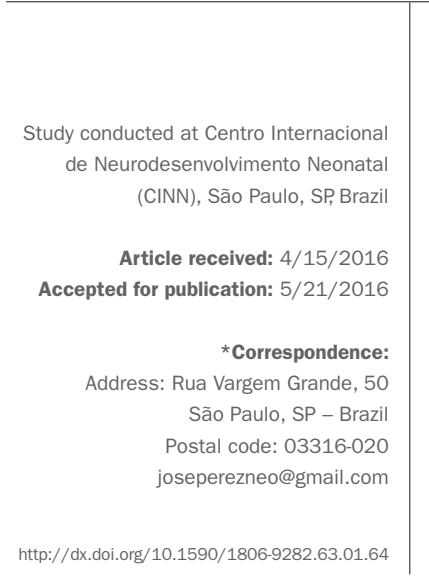

\section{SUMMARY}

Hypoxic ischemic encephalopathy is a major complication of perinatal asphyxia, with high morbidity, mortality and neurologic sequelae as cerebral palsy, mostly in poor or developing countries. The difficulty in the diagnosis and management of newborns in these countries is astonishing, thus resulting in unreliable data on this pathology and bad outcomes regarding mortality and incidence of neurologic sequelae. The objective of this article is to present a new clinical diagnostic score to be started in the delivery room and to guide the therapeutic approach, in order to improve these results.

Keywords: asphyxia, hypoxic ischemic encephalopathy, Siben Neurological Score.

\section{INTRODUCTION}

Hypoxic ischemic encephalopathy (HIE) is a disease with a strong potential to cause cerebral palsy. Depending on its severity, it may turn into an emotional, social, and economic tragedy for the individual and their entire family, as well as society as a whole.

The pathophysiology of HIE has been described in detail, with a primary phase leading to neuronal apoptosis $^{1}$ and a secondary reperfusion phase that occurs about six hours after the hypoxic ischemic insult, with various types of response that may lead to a secondary neuronal injury, compatible with the presence of neurologic sequelae in the newborn.

HIE is characterized by neurological symptoms of variable severity, and is classified as mild, moderate and severe. The condition is accompanied by the involvement of one or more organs and may lead to multiple organ failure. The symptoms vary according to the severity of the disease and whether there is central nervous system involvement, ranging from deterioration of wakefulness up to seizures and coma; or from a multi-organ point of view, involvement of the digestive tract (from vomiting up to symptoms of necrotizing enterocolitis), the urinary tract (from oliguria up to acute renal failure ${ }^{5}$ ), the respi- ratory system (pulmonary hemorrhage up to pulmonary hypertension ${ }^{2}$ ) and the cardiovascular system, often with sinus bradycardia ${ }^{3}$ (predominance of the parasympathetic system), and, finally, metabolic disorders (calcium, glucose and magnesium ${ }^{4}$ ). All of these changes may aggravate the involvement of the central nervous system.

Currently, perinatal asphyxia associated with moderate or severe HIE, which is its main complication, affects between 1-2/1,000 live births in developed countries and is estimated at affecting between 10-20/1,000 live births in poor or developing countries, ${ }^{6}$ being responsible for $1 / 3$ of neonatal mortality in these countries. However, we believe that the actual incidence of HIE in poor and/or developing countries is unknown. What we do know is that in Brazil 13 to 15 newborns die every day as a result of asphyxia, according to a study by the resuscitation committee of the Brazilian Pediatric Society. ${ }^{7}$ There are several factors making us unaware of our HIE rate, as published by Perez. ${ }^{8}$ These include the difficulty presented by health teams to assess the newborns neurologically, or a belief that an Apgar score of $>5$ at $5^{\prime}$ or 10' is sufficient and necessary to rule out the diagnosis of HIE. A total lack of preparedness among health teams in relation to the use of neurological scores for the newborn or the 
total lack of their use at some centers is prevalent. These are some of the factors leading us to believe that the actual incidence of HIE is higher than that already published. Having an easy-to-use clinical evaluation mechanism from the moment of birth would favor the obtainment of a more realistic notion of the importance of this pathology in Brazil and in all developing countries, as well as a better therapeutic outcome for such patients.

\section{Objective}

To present a simple clinical neurological score for hypoxic ischemic encephalopathy developed by the Iberoamerican Society of Neonatology (Siben) and a flow chart to guide the diagnosis and management of newborns who have suffered some degree of asphyxia.

\section{DiagnOSIS OF HIE AND DESCRIPTION OF THE Siben HIE SCORE}

Considering a maternal obstetric history with the identification of hypoxic ischemic insult (e.g. umbilical cord prolapse, uterine rupture) associated with the presence of a low Apgar score and umbilical cord $\mathrm{pH}$ with acidosis $\leq 7.1$ leads us to a diagnosis of HIE. However, proper neurological clinical examination of the newborn is essential to confirm the diagnosis.

In order to systematize this neurological assessment of newborns, several neurological scores have been created for newborns, such as the currently available Sarnat and Sarnat, ${ }^{9}$ Thompson, ${ }^{10}$ and Garcia-Alix ${ }^{11}$ scores, as well as others. None of these have been applied since the first minutes of life, and some of them are complex and/or use supplementary exams.

In our view, a neurological score, including only clinical aspects that can be started as soon as we finish the Apgar score, is essential. Therefore, we have developed the neurological score presented in Table 1.

This scale assesses ten clinical aspects and is very simple to perform. As HIE has been previously classified as mild, moderate or severe, each item evaluated varies according to the degree of severity. For example, if spontaneous activity is absent, the corresponding item is found in severe HIE (Table 1). A point is given to every item that corresponds to a level in the Siben score, with the diagnosis of HIE considered as strongly suspect at a certain level, in the presence of three points or more. In the event of finding items at different levels, the level with the most items found will predominate. For example, if a slight change in the level of consciousness, such as being hyperalert, and a change in posture with mild distal flexion and weak suction are found in a newborn with a history of a hypoxic ischemic insult, we could classify this newborn as presenting mild HIE. However, if convulsions, bradycardia, hypotonia, and a weak Moro reflex are presented in association, we have a case in which signs of moderate HIE predominate over the mild condition, and this should be the established diagnosis. In short, the mild, moderate or severe HIE diagnosis will predominate according to the highest number of items (always above three) found in the corresponding level.

The neurological score that we have developed is shown in Table 1, and is called the HIE Score of the Iberoamerican Society of Neonatology.

We use the Siben Neurological Score for all infants who have an Apgar $\leq 5$ in the first, fifth or tenth minute, and we begin using it in the delivery room as soon as the Apgar score is concluded. A diagnosis made as early as possible will guide the treatment and possibly lead to a more favorable outcome in the clinical case.

Unlike other neurological scores, our tool only relies on clinical criteria for the score, which greatly facilitates clinical monitoring and, in our opinion, the early diagnosis or early suspected diagnosis of HIE. In many centers with high birth rates, prompt evaluation by a pediatric neurologist with experience in neonatology, the possibility of performing electroencephalography (EEG) with an integrated amplitude or an early conventional EEG, a very early magnetic resonance imaging (MRI) examination and laboratory tests (umbilical cord blood gases, creatine phosphokinase - CPK, lactic dehydrogenase - LDH, and others) are not available in the first hours of life or even afterwards, especially in poor or developing countries.

For the implementation of this clinical score it is important to train the medical and paramedical teams, as well as to print and distribute a copy of the score to all team members, and posting it in all sectors of the neonatology unit.

\section{VALIDATION OF THE SCORE}

No one argues that clinical assessment is essential in neonatology, and our score adds the possibility of a better clinical assessment of newborns from the delivery room onwards. To date, we have used this score in three neonatal units to assess 26 newborns with a gestational age of over 35 weeks and suspected diagnosis of HIE while in the delivery room. All of these newborns had an Apgar score $1^{\prime} \leq 3$ and presented a Siben score of 3 or more points in the delivery room after completion of the Apgar score, or were sent to the neonatal intensive care unit (NICU) with strong suspicion of HIE. The diagnosis was confirmed in all newborns based on the development of the clinical 


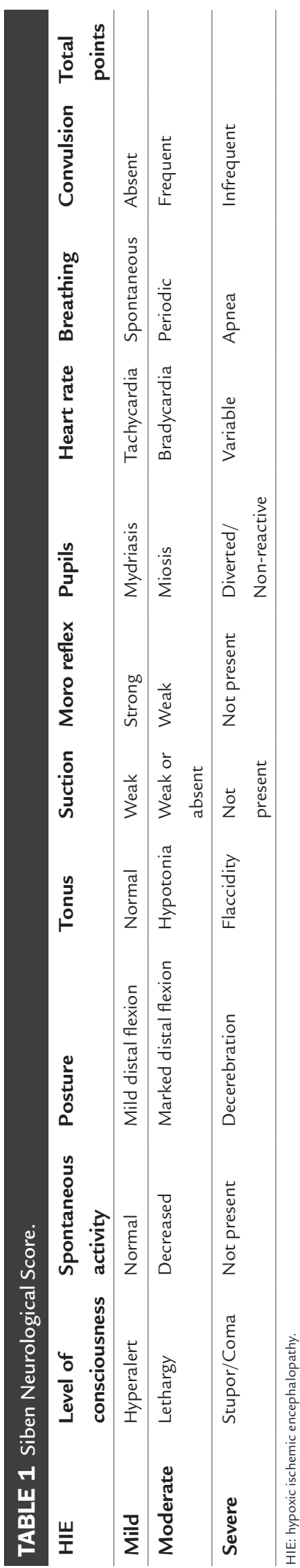


condition (emergence of seizures, apnea, bradycardia or tachycardia, pupil changes, change in tonus, and eventual death) and all showed high levels of CPK and LDH. All of the newborns underwent therapeutic hypothermia. Seven newborn babies progressed to death (27\%) and the remaining 19 underwent MRI after 7 days of life. Six infants did not show any alterations in the MRI examination, ten infants had some degree of damage to the basal ganglia and three newborns had damage to the gray matter. The alterations presented by these 13 newborns were compatible with the diagnosis of hypoxic ischemic insult with subsequent progression to HIE (Table 2).

All of the assessors were unanimous in reporting ease of use from the delivery room onwards and in the sequential neurological assessment of the newborn, greatly facilitating the diagnosis of HIE and progressive HIE, in which the patient shows progressive clinical neurological deterioration that can progress from mild to serious symptoms in a few hours. ${ }^{12}$ It is very likely that in every center in which this clinical score is implemented there will be no more undiagnosed cases, with at least a suspected diagnosis of HIE, and we can use therapeutic measures sooner, including therapeutic hypothermia, preventing delayed diagnosis and administration of the appropriate therapy. The next step in the evaluation and validation will be to compare the statistics and the monitoring of patients managed using this score.
With the advances that have occurred in recent years to improve neonatal outcomes in newborns with HIE, the establishment of an algorithm for the management of HIE is fundamental, in addition to prevention and early diagnosis, as described below.

\section{HIE MANAGEMENT ALGORITHM}

Seeking to facilitate the management of newborns with suspected HIE and/or diagnosed with HIE, we have developed an algorithm to guide the management of newborns from the delivery room onwards in different clinical situations.

The importance of the Siben score for HIE lies in the fact that it is a clinical score that is easy to conduct. Below, we will describe an algorithm with measures to evaluate and manage newborns based on their resulting score. Obviously, the need for resuscitation with or without cardiac massage, the need for access to central vessels, mechanical ventilation, and drugs will be undertaken according to the general conditions of the newborn and according to the protocols used, as well as the provision of the general basic required by the newborn. The $\mathrm{pH}$ and/or excess base obtained in the umbilical cord blood or soon after birth may be useful, but not always available. A pH $<7.1$ and/or BE $>-14$ has an acceptable positive predictive value; however, they are not pathognomonic of HIE. A pH and/or BE close to normal does not have negative predictive value. Therefore, if the clinical score demonstrates moderate or severe degree,

TABLE 2 Clinical alterations compatible with HIE.

\begin{tabular}{|c|c|c|c|}
\hline & n (\%) & $\begin{array}{l}\text { Magnetic resonance imaging with more than } \\
7 \text { days of life }(n=19)\end{array}$ & n (\%) \\
\hline Lethargy & $18(69.2 \%)$ & & \\
\hline Stupor/Coma & $5(19.2 \%)$ & & \\
\hline Mild distal flexion & $9(34.6 \%)$ & Normal & $6(31.5 \%)$ \\
\hline Marked distal flexion & $12(46.15 \%)$ & & \\
\hline Decerebration & $5(19.2 \%)$ & & \\
\hline Hypotonia & $16(61.5 \%)$ & Changes in the basal ganglia & $10(52.63 \%)$ \\
\hline Flaccidity & $10(38.4 \%)$ & & \\
\hline Weak suction & $18(69.2 \%)$ & Alterations to the gray matter & $3(15.78 \%)$ \\
\hline No suction & $8(30.7 \%)$ & & \\
\hline Weak Moro reflex & $19(73.07 \%)$ & & \\
\hline No Moro reflex & $7(26.9 \%)$ & & \\
\hline Pupils mydriasis/miosis & $20(76.9 \%)$ & & \\
\hline Non-reactive pupils & $6(23.07 \%)$ & & \\
\hline Bradycardia & $14(53.8 \%)$ & & \\
\hline Bradycardia/Tachycardia & $12(46.15 \%)$ & & \\
\hline Periodic respiration & $20(76.9 \%)$ & & \\
\hline Apnea & $6(23.07 \%)$ & & \\
\hline Convulsions & $14(53.8 \%)$ & & \\
\hline
\end{tabular}


this should not be ignored even with a $\mathrm{pH}>7.1$. Similarly the CPK and LDH dosages have no prognostic value and are not useful, in isolation, for a therapeutic decision. Furthermore, the laboratory results of enzymes may not be available or it may take several hours to obtain these results.

The flowchart can guide the management of newborns with clinical symptoms compatible with that described, facilitating treatment (Figure 1).

\section{TREATMENT}

To prevent hypocapnia (cerebral hypoflow) or hypercapnia (cerebral hyperflow) during mechanical ventilation. To prevent hyperthermia (accelerates the phenomenon of neuronal apoptosis) and hyperoxemia (causes oxidative stress), increasing the risk of neuronal damage. To correct any occasional metabolic disturbances (hypocalcemia, hypoglycemia, and hypomagnesemia) that can worsen the clinical condition.

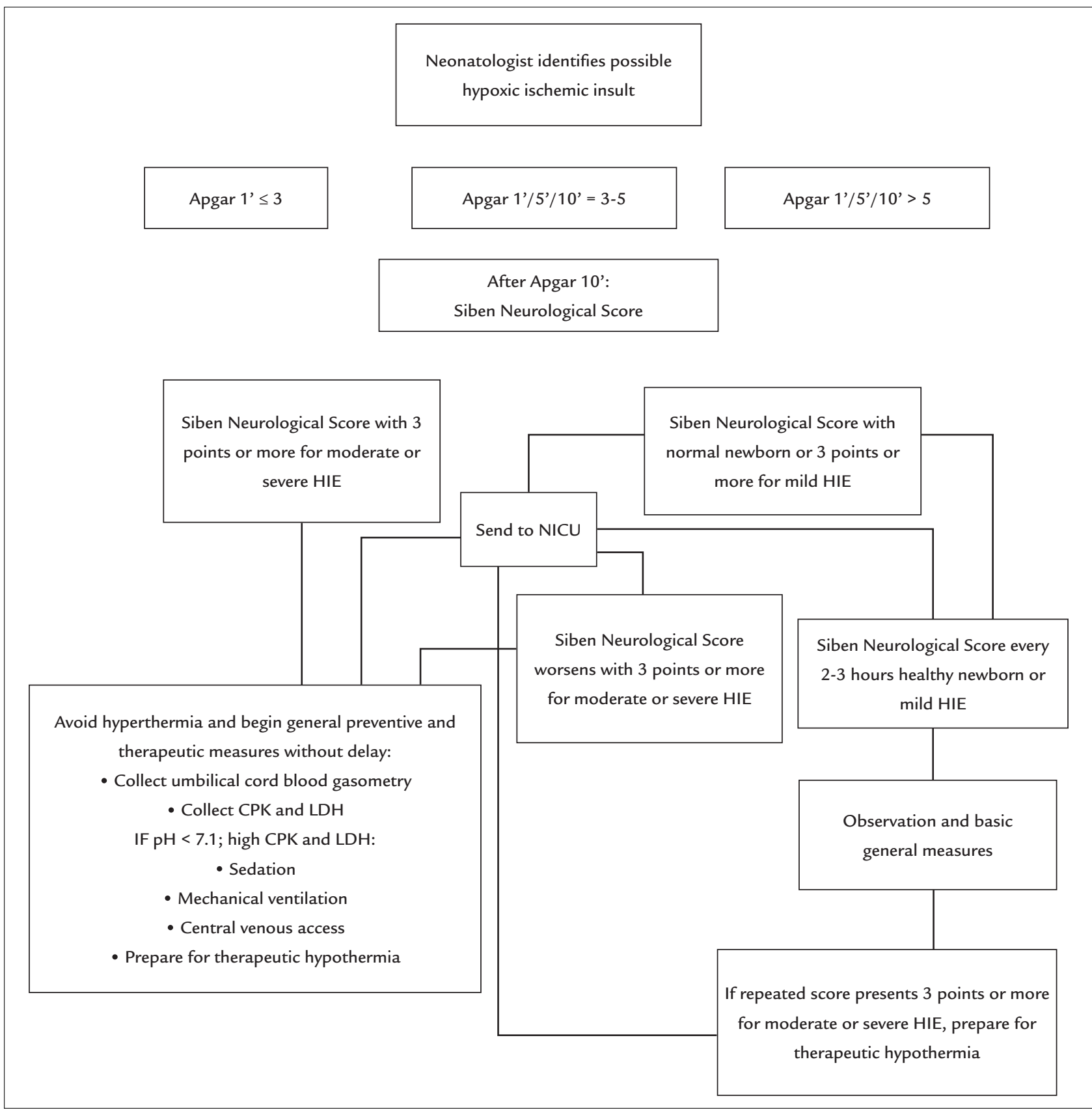

FIGURE 1 The flowchart summarizes the basic preventive and therapeutic measures of the Siben Neurological Score. HIE: hypoxic ischemic encephalopathy; CPK: creatine phosphokinase; LDH: lactic dehydrogenase; NICU: neonatal intensive care unit. 
Therapeutic hypothermia is a therapeutic strategy with scientifically proven benefits. However, the disparity of the effectiveness of this therapy in developed and poor and/or developing countries is clear, ${ }^{13}$ demonstrating advantages in the use of equipment with Servo control and the supply of heat by convection. ${ }^{14}$

In three studies already published, ${ }^{15,16}$ we have presented an alternative to the use of a device developed in São Paulo (Brazil), the Neonatflow, with Servo control and supply of heat by convection, as well as humidity and isolation through the laminar flow system. We believe that this device facilitates the treatment of these patients, especially in poor and/or developing countries, where the incidence of HIE is highest.

The basic measures to be adopted in a patient with a diagnosis of moderate or severe HIE based on the Siben score will initially be to avoid hyperthermia, by turning off the radiant heat cradle or the incubator or adjusting the desired central temperature by servo control if using the Neonatflow in order to maintain the central temperature between $33-34^{\circ} \mathrm{C}$ for 72 hours. With regard to the ventilatory part, prevent hypoxia and hyperoxia, hypocapnia and hypercapnia, promote continuous sedation through central venous access, bladder catheterization and installation of the EEG, if available.

\section{Conclusion}

The use of this clinical score can improve the objectivity of the assessment and monitoring of newborns and the early start of treatment. The use of the Siben Neurological Score proved to be easy to implement and provided a more objective and early diagnosis of HIE. It may be of greater value in poor and/or developing countries, or in neonatal units without access to high-cost diagnostic examinations (imaging, laboratory, and others).

\section{Conflict of interest}

José Maria Rodriguez Perez is one of the patent holders of the Neonatflow device.

\section{Resumo}

Escore clínico de encefalopatia hipóxico-isquêmica da Sociedad Iberoamericana de Neonatología (Siben): uma nova proposta para seu diagnóstico e manejo perinatal

A encefalopatia hipóxico-isquêmica é a principal complicação da asfixia perinatal, com alta morbidade, mor- talidade e incidência de sequelas neurológicas, como a paralisia cerebral, principalmente em países pobres e/ou em desenvolvimento. Nessas regiões, as dificuldades no diagnóstico e no manejo desses recém-nascidos é surpreendente, o que resulta em dados pouco confiáveis e em péssimos desfechos tanto no que se refere à mortalidade como à incidência de sequelas neurológicas. $\mathrm{O}$ objetivo deste artigo é apresentar um novo escore para o diagnóstico clínico ser iniciado na sala de parto e uma abordagem terapêutica com o intuito de melhorar esses resultados.

Palavras-chave: asfixia, encefalopatia hipóxico-isquêmica, Escore Neurológico Siben.

\section{References}

1. Perez JMR, Feldman A, Alpan G. Treating hypoxic ischemic encephalopathy with hypothermia. NeoReviews. 2015; 16(7):e413-9.

2. Kinsella JP, Abman SH. Recent developments in the pathophysiology and treatment of persistent pulmonary hypertension of the newborn. J Pediatr. $1995 ; 126(6): 853-64$

3. Rowe RD, Hoffman T. Transient myocardial ischemia of the newborn infant: a form of severe cardiorespiratory distress in full-term infants. J Pediatr. 1972; 81(2):243-50

4. Collins JE, Leonard JV. Hyperinsulinism in asphyxiated and small-for-dates infants with hypoglycaemia. Lancet. 1984; 2(8398):311-3.

5. Tsang RC, Chen IW, Hayes W, Atkison W, Atherton H, Edwards N. Neonatal hypocalcemia in infants with birth asphyxia. J Pediatr. 1974; 84(3):428-33.

6. Lawn J, Shibuya K, Stein C. No cry at birth: global estimates of intrapartum stillbirths and intrapartum-related neonatal deaths. Bull World Health Organ. 2005; 83(6):409-17.

7. Almeida MFB, Guinsburg R, Santos RM, Moreira LMO, Anchieta LM, Daripa M; Coordenadores Estaduais do Programa de Reanimação Neonatal da SBP. Brasil, 2005 e 2006: cinco recém-nascidos a termo sem malformações congênitas morrem com asfixia ao nascer a cada dia. In: XX Congresso Brasileiro de Perinatologia; 2010 Nov 21-24; Rio de Janeiro, RJ.

8. Perez JMR. Correlation between Apgar score and hipoxic-ischemic encephalopathy. Correspondence. Rev Assoc Med Bras. 2015; 61(3):1.

9. Sarnat HB, Sarnat MS. Neonatal encephalopathy following fetal distress. Obstet Gynecol Surv. 1977; 32(5):295.

10. Thompson CM, Puterman AS, Linley LL, Hann FM, van der Elst CW, Molteno $\mathrm{CD}$, et al. The value of a scoring system for hypoxic ischaemic encephalopathy in predicting neurodevelopmental outcome. Acta Paediatrica. 1997; 86(7):757-61

11. Martín-Ancel A, García-Alix A, Gayá F, Cabañas F, Burqueros M, Quero J. Multiple organ involvement in perinatal asphyxia. J Pediatr. 1995; 127(5):786-93.

12. Gagne-Loranger M, Sheppard M, Ali N, Saint-Martin C, Wintermark P Newborns referred for therapeutic hypothermia: association between initial degree of encephalopathy and severity of brain injury (what about the newborns with mild encephalopathy on admission?). Am J Perinatol. 2015; 33(2):195-202

13. Montaldo P, Pauliah SS, Lally P, Olson L, Thayyil S. Cooling in a low-resource environment: lost in translation. Semin Fetal Neonatal Med. 2015; 20(2):72-9.

14. Perez JMR, Golombek S, Alpan G, Fajardo CA, Sola A. Comparison of hypothermia for hypoxic-ischemic encephalopathy with a laminar flow unit (neonatflow) vs. NICHD trial. Vancouver: Pediatric Academic Society; 2014

15. Perez JMR, Golombek S, Fajardo C, Sola A. A laminar flow unit for the care of critically ill newborn infants. Med Devices (Auckl). 2013; 6:163-7.

16. Perez JMR, Golombek S, Alpan G, Sola A. Using a novel laminar flow unit provided effective total body hypothermia for neonatal hypoxic encephalopathy. Acta Pediatr. 2015; 104(11):e483-8. 